\title{
EE Course Planning Software System
}

\author{
Mohammad Shakeel Laghari* \\ Department of Electrical Engineering, UAE University, P.O. Box: 15551, Al Ain, United Arab Emirates. \\ * Corresponding author. Tel.: 00971506625492; email: mslaghari@uaeu.ac.ae \\ Manuscript submitted November 25, 2017; \\ doi: 10.17706/jsw.13.4.219-231
}

\begin{abstract}
Student course planning at the Department of Electrical Engineering (EE), UAE University, is important to ensure that a student fulfills the degree requirements of the university in an organized way, without encountering any redundant delays. Although the UAE University has a well-established Banner Registration System, however, course planning performed by the faculty and staff at department and college level sometimes is short of required expertise and qualification. Students have faced problems due to lack of a proper advising system as well as an inadequacy of seeking proper advice. An EE Course Planning Software System (EE-CPSS) package is devised in this respect. The software is developed by using the Python computer programming language. This system helps students in selecting from four to seven most suitable courses to register in the next semester. The outcome of the course selection is stored in a file for future reference.
\end{abstract}

Key words: Academic advising, course planning, python, software package.

\section{Introduction}

Course planning and academic advising is a anticipation to exchange information intended to help students reach their educational goals. It is an understanding and shared responsibility between an adviser (faculty or staff) and the student. Advising takes place in situations where an academic representative advises a university or college student about requirements needed for degree completion and other academic matters that include course and career planning and typical discussions on how a course of study fits a particular academic or career interest [1]-[4].

Course registration comprises of three main sections: what a student needs to know before registration, guidelines for registering, and what the next steps are after the student is done. The process of registering and the after steps are well established, however, the knowledge of what courses to register is a significant process often known as course planning.

Typical registration problems that are based on course planning and advising include advised or chosen courses with time conflicts or greater time apart, preferred electives bypassing specialization requirements and restrictions, missed out on courses specific for alternating semesters, chosen too many courses or too few courses in a specific semester, etc. Students in this category suffer with problems such as; class expulsion after the initial attendance period because of prerequisite requirements, delayed graduation because of unnecessary or missed out courses, dropping a complete semester because of minimum number of course requirements, or having a heavy semester load because of too many courses, etc.

The devised EE-CPSS package helps and guides students in selecting from four to seven most appropriate courses suitable to register in the next semester. A typical course selection procedure starts with the 
student uploading a list of the passed/current semester courses. The software package then evolves through several procedures to advise student with an optimum list of the most suitable courses. The course selection is based on a priority process that includes a knowledge area build around all EE courses. The paper describes complete operation of the planning package that includes prioritized course selection, help menus, restrictions, etc.

\section{Background Information}

Early course registration process involved students to register directly with their respected departments. Those early processes were concerned with delays, resources, and logistics. Later, academic institutions addressed this perspective of registration from many viewpoints including student course planning, course advising, course registration, class scheduling, and other related issues.

The trend of all above issues increased to near double with the expansion of post-secondary education in the late 1990s. This expansion had an indirect effect on the institution's enrolment as the number of students has also increased. As the demand is stabilized so is, a need to restructure the registration process that maximizes the allocation of course places and increases the number of registered students.

Moreover, the institutions, in general, have progressed to offer sophisticated programs that are specialized as well as multidisciplinary. The increased number of programs has introduced time conflicts while selecting the courses. The required registration system was developed to provide real time registration for students and enable students to maximize their opportunities in registering courses of their own interest as well as advising students in completing their degree requirements in an optimum way.

With many advantages of the computerized registration systems, the major hitch was to tolerate machine and network failures. It was hoped that most human errors, such as incorrectly inputting data, would be detected by the system as they occurred, but it was expected that some "off-line" data manipulation would be necessary for errors that had not been foreseen.

Therefore, the success of any attempt to computerize this activity depended on the reliability, availability and integrity of the computer systems, both software and hardware, on which the registration programs are run. As many of the departments have most likely made significant investments in computer hardware, it is logical that no specialized hardware is to be purchased and software fault-tolerance is to be used instead.

The authors in this research present a Decision Support System (DSS) for student advising. The system aims to provide students with an automated program planning and scheduling service that best fits their profiles while meeting academic requirements [5].

The investigation presented in the paper integrates conventional advisors' advising and web-based advising to form a student-centric advising model to engage undergraduate students actively in their education process. The primary focus of the system was to provide educational planning and advising resources in support of student's academic objectives [6].

The authors of this paper have described the design and development of a Web-based advising system that supplements the conventional advising process. The system's goals include minimizing repetitive tasks performed by advisors, to encourage students to adopt a proactive attitude towards advising, to make advising related information available to remote students in a single place, in electronic format, and to minimize inconsistencies in the advising process [7].

This paper describes an Advisement System designed to mitigate the issues of an out of-the-box implementation at a southeastern university to help improve retention and graduation [8].

The aim of this paper was to discover the main key area requirements for web-based academic advising system. The research uses a combination of approaches. The research resulted in the proposed conceptual 
framework of web-based academic advising information system [9].

Another development was completed at the Wylie College IT for software architectural development of a course registration system using the specifications created for the college requirements. The Software Architecture Document provides an architectural overview of the C-Registration System. The C-Registration System was initiated by Wylie College IT to support online course registration [10].

A Web-based decision support tool for academic advising was devised. The authors attempt to solve a technology-based last mile problem by developing and evaluating a web-based decision support tool (the Online Advisor). This tool helps advisors and students make better use of an already present student information system [11].

A Student Advising Software (SAS) was developed using JAVA computer programming language. The system helped and guided students in selecting appropriate courses suitable to register online with the Banner System. The outcome of the course selection was stored in a file to show a complete typical plan [12].

[ELEC_305, 2, 2, 7, 0]

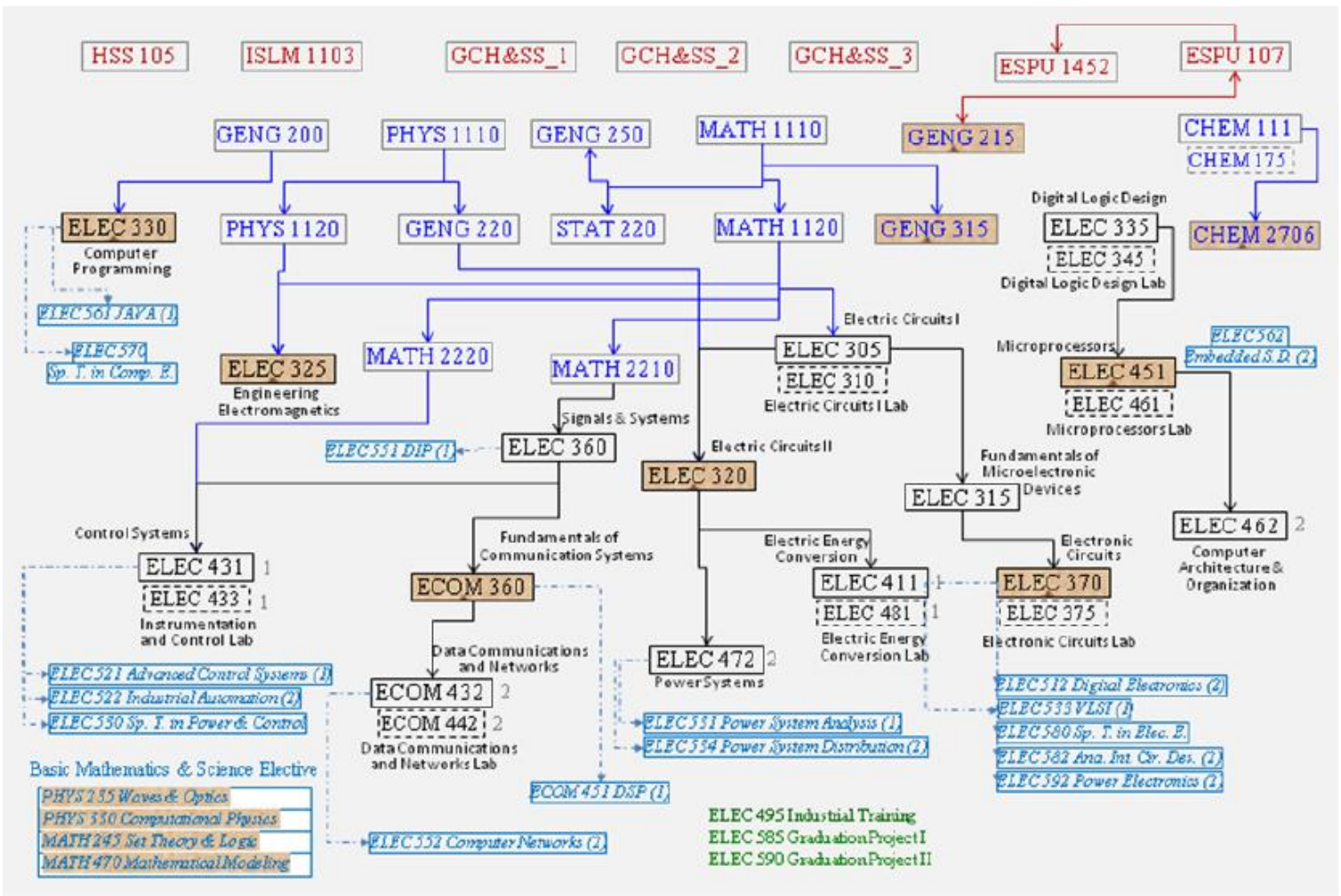

Fig. 1. EE course chart showing all 67 courses with hierarchies.

An improved version of course advising \& planning software was developed at the EE Department, UAE University. It is again a manual system with limited functionality and about a $20 \%$ error rate [13].

An automated course advising system based on the new curriculum to show a complete typical plan (semester-wise) has recently been developed that includes prioritized course selection [14].

The authors in this paper developed a course planning system for one semester with six prioritized fields but with limited functionality and about $15 \%$ error rate [15].

An improved version of course planning system is developed by using Java for all remain semesters by using six prioritized fields with improved functionality [16].

A priority based course planning and advising system has been developed by using Java programming 
language. The software system uses five prioritized fields [17].

An expert system using JESS (a JAVA based rule engine and scripting environment) was developed that allowed students to seek quick responses to their queries regarding their plan of study and progress in the program [18].

The academics at the Florida Atlantic University developed a similar web-based advising system that supplemented the conventional advising process [19].

A Bayesian Network model for planning course registration and advising by using a data mining technique was developed to predict the sequences of courses to be registered by undergraduate students whose majors are computer science or engineering [20].

Project planning techniques for academic advising and learning was devised in which the author proposed that by applying project management concepts, tools, and techniques, undergraduate degree program advising and planning can be improved [21].

Two project management tools were designed to help the students complete their degree plan in an expressway. The first tool provided a visualization map of course sequences, customized for each student, making advising adjustments that optimized the time to obtain the degree under a constrained set of resources. The second tool collected information from multiple students through several semesters and was used to identify bottlenecks in the curriculum [22].

An automatic dialog system for student advising is devised. The general purpose of this project was to design and implement an automatic dialog system for augmenting university student advising [23].

A web-based multidisciplinary advising system is presented that can be utilized by students, advisors, course timetable planners, and heads of departments. Students are given informative advice through web-based services to help them make best decisions towards a successful degree of their choice. These services, such as registering for courses to stay on the right degree path; consist of a dependency graph that shows their progress in their degree plan [24].

A web-based user interface design for semester course registration system is presented. A typical student registers in the website and gives his priority of courses whereas the course coordinator selects courses [25].

\section{The EE-CPSS Package}

The UAE University has roughly 14,000 students including 2,200 engineering college students. Electrical Engineering is one of the five departments where students take 147 credit hours to fulfill the B.Sc. degree requirements. Typically, the students take from nine (minimum) to 12 (maximum) semesters to complete their degree requirements with an average course load of from 12 to 18 credits and from four to seven courses per semester.

The 147 credit hours (51 courses) of degree load is divided into General Education Requirements - 21 credits (seven courses) including three general education electives, College Requirements - 41 credits (15 courses), Compulsory Specialization Requirements - 52 credits (22 courses) including seven, 1-credit Labs., Elective Specialization Requirements including one Basic Mathematics \& Sciences elective - 12 credits (three + one course), Industrial Training - 15 credits (one course), and Graduation Projects - 6 credits (two courses).

An id selection process downloads a student courses file. The course file is basically a list of all completed and current semester registered courses. The software package downloads another file containing a list of all courses offered in the investigating semester of Spring 2017. These courses include cores and electives. Others are three electives from general education courses chosen from a General Education/Humanities \& Social Sciences course pool. 
The offered courses are specific for Spring semester only however, there is an alternate set of core and elective courses that are offered for the other semester (Fall) of the year. Course planning system for next two semesters in contrast to the currently developed one, will be investigated in an improved version of the software package.

Fig. 1 shows a hierarchical chart of 67 courses including 16 Elective Specialization (students chose three) and four Basic Mathematics \& Science elective (students chose one). A '1', '2', or no number next to the course block indicates the course offered is in either Fall, Spring, or both semesters, respectively. For example, ELEC 431 is offered in the $1^{\text {st }}$ semester only, whereas ECOM 432 is offered in the $2^{\text {nd }}$.

The red colored font courses are the General Education Requirements courses, blue colored are the College Requirements, whereas the black colored are Compulsory Specialization Requirements. The elective courses are shown in light blue color pointed either by arrows or are underneath the major course blocks. For example, electives ELEC 521, ELEC 522, and ELEC 530 are chosen based on the core course ELEC 431 (Control Systems). The electives offering semesters are also shown with either a '(1)' or a '(2)' next to course names. The Basic Mathematics \& Sciences electives are also shown in light blue course blocks. The laboratory or Lab. course blocks (in dashed lines) are shown under the main course blocks.

Industrial training is one full semester course load with the registration requirements of acquiring more than 93 credit hours of course work however, the students typically target 100 credits before progressing for industrial training as this leaves them a course load of six courses for each of the final two semesters before graduation. The prerequisite courses for industrial training are shown as highlighted blocks (for example, ELEC 320, ELEC 325, etc.). The Industrial Training and Graduation Projects courses are shown in green color.

The prerequisite hierarchies in the chart are shown by one directional arrows whereas the co-requisite courses are connected with two directions arrows (for example, the prerequisites for ELEC 325 are PHYS 1120 and MATH 1120, whereas GENG 250 and STAT 220 are co-requisites).

The 67 courses shown in Fig. 1 are divided into two sets with one set of courses required for industrial training and another set of courses needed for graduation. The first set is prioritized over the second as there are several courses knowledge required for industrial training.

The software package creates and stores a file that contains a sub-set (in reduced number) of all courses offered in the Spring 2017 semester. This subset is dependent on the student course file that contains information on all passed and current semester courses. Therefore, the courses belonging to this sub-set file are those, whose prerequisite requirements are fulfilled by the student in the current and/or previous semesters.

The student final course selection is based on this reduced sub-set (from 10 to 15 courses) rather than typical 50 odd offered courses offered in a specific semester. However, this final course selection is not the students' choice but is inherent in the devised system. A final selection of from four to seven courses is achieved with a devised knowledge area build around all 67 courses. The knowledge area for each individual course is build and defined by the following course example.

The ELEC 305 (Electric Circuits I) compulsory course is appended with four digits of knowledge area.

The $1^{\text {st }}$ digit specifies a reverse hierarchy of the number of courses taken before this course. A ' 2 ' here is an indicative of two levels of courses before this course, which are MATH 1120 and MATH 1110 for ELEC 305. The idea here is the hierarchal importance of a specific course.

The $2^{\text {nd }}$ digit points at the number of courses that are opened by this course in the immediate next semester. Definitely, a course with a higher number here is prioritized over others because it opens more choices for the semester after the next. Elective specialization courses are not included in this knowledge area field. A ' 2 ' in this field for ELEC 305 indicates that there are two courses opened by this course, which 
are ELEC 315 and ELEC 320. Whereas the attached Lab. course of ELEC 310 is a co-requisite and is taken at the same level (shown with a dashed lined block in Fig. 1). All Lab. courses have similar associations as with the theory courses.

The $3^{\text {rd }}$ digit indicates the opening of a total number of courses dependent on this course. Again, a higher number in this field is an indication of its priority over others. A ' 7 ' here shows that there are seven courses that opens in the next or more hierarchal levels for ELEC 305 and these courses are ELEC 315, ELEC 320, ELEC 370, ELEC 375, ELEC 411, ELEC 472, \& ELEC 481. Here a Lab. course is also included in the count.

The $4^{\text {th }}$ digit indicates the number of elective specialization courses opened by this course. A ' $O$ ' in this field for ELEC 305 indicates that there are no elective course(s) dependent on this course.

All four fields are prioritized from highest to lowest with the first field having the highest priority. Table I shows a list of all course required for Industrial Training course of ELEC 495.

Table 1. Industrial Training Course List with Associated Knowledge Area

\begin{tabular}{|c|c|c|}
\hline Course Name & $\begin{array}{l}\text { Course } \\
\text { Code }\end{array}$ & $\begin{array}{c}\text { Knowledge } \\
\text { Area }\end{array}$ \\
\hline English for Engineering & ESPU 107 & $0,0,0,0$ \\
\hline Communication Skills for Engineering & ESPU 1452 & $1,0,0,0$ \\
\hline Introduction to Programming (2) & GENG 200 & $0,1,1,0$ \\
\hline Engineering Ethics (2) & GENG 215 & $0,0,0,0$ \\
\hline Engineering Thermodynamics & GENG 220 & $1,1,4,0$ \\
\hline Engineering Statistics & STAT 220 & $1,0,0,0$ \\
\hline Freshman Laboratory (2) & GENG 250 & $0,0,0,0$ \\
\hline Calculus I for Engineering & MATH 1110 & $0,3,21,0$ \\
\hline Calculus II for Engineering & MATH 1120 & $1,5,18,0$ \\
\hline Differential Equations for Engineering & MATH 2210 & $2,1,6,0$ \\
\hline Linear Algebra for Engineering & MATH 2220 & $2,2,2,1$ \\
\hline Physics I for Engineering (4) & PHYS 1110 & $0,2,7,0$ \\
\hline Physics II for Engineering (4) & PHYS 1120 & $1,1,1,0$ \\
\hline General Chemistry I & CHEM 111 & $0,1,1,0$ \\
\hline Chemistry I Laboratory for Engineering (1) & CHEM 175 & $0,1,1,0$ \\
\hline Engineering Economics & GENG 315 & $1,0,0,0$ \\
\hline Materials Science & CHEM 2706 & $1,0,0,0$ \\
\hline Electric Circuits I & ELEC 305 & $2,2,7,0$ \\
\hline Electric Circuits I Laboratory (1) & ELEC 310 & $2,2,7,0$ \\
\hline Fundamentals of Microelectronic Devices & ELEC 315 & $3,2,2,0$ \\
\hline Electric Circuits II & ELEC 320 & $3,3,3,0$ \\
\hline Engineering Electromagnetics & ELEC 325 & $2,0,0,0$ \\
\hline Computer Programming & ELEC 330 & $1,0,0,2$ \\
\hline Digital Logic Design & ELEC 335 & $0,1,2,0$ \\
\hline Digital Logic Design Laboratory (1) & ELEC 345 & $0,1,2,0$ \\
\hline Signals \& Systems & ELEC 360 & $3,3,5,1$ \\
\hline Fundamentals of Communication Systems & ECOM 360 & $4,2,2,1$ \\
\hline Electronic Circuits & ELEC 370 & $4,0,0,5$ \\
\hline Electronic Circuits Laboratory (1) & ELEC 375 & $4,0,0,5$ \\
\hline Microprocessors & ELEC 451 & $1,1,1,2$ \\
\hline Microprocessors Laboratory (1) & ELEC 451 & $1,1,1,2$ \\
\hline Waves \& Optics & PHYS 235 & $0,0,0,0$ \\
\hline Computational Physics & PHYS 330 & $0,0,0,0$ \\
\hline Set Theory and Logic & MATH 245 & $0,0,0,0$ \\
\hline Mathematical Modeling & MATH 470 & $0,0,0,0$ \\
\hline
\end{tabular}

All courses are appended with their associated knowledge areas based on the course structure, level and hierarchy. Again, the courses are separated in terms of color coding font. General Education Requirements 
courses are in red color. College Requirements courses in blue color. Compulsory Specialization Requirements (core) courses in black color. Industrial Training and the Graduation Projects courses are shown in green color and all electives in light blue color.

All courses are typically 3-credits except for some courses with different credit hours as shown in Table I. Table II shows a list of all other courses not required for industrial training.

\section{Test Cases}

Examples of four typical student course plans with different sets of completed courses are shown. The first example student (with university id \#: 200935136) has completed 23 out of 51 courses required for graduation. Fig. 2 shows the operations of the software package. The system displays all 67 courses and another list of 50 courses offered in the Spring Semester of 2017. The system evolves to show 11 possible courses, which the student is eligible to take as the prerequisite requirements for these courses are satisfied as shown in Table III.

Table 2. Graduation Course List with Associated Knowledge Area

\begin{tabular}{lcc}
\hline \hline Course Name & Course & Knowledge \\
& Code & Area \\
\hline Emirates Studies & HSS 105 & $0,0,0,0$ \\
Islamic Culture & ISLM 1103 & $0,0,0,0$ \\
General Culture/Humanities \& Social Sciences 1 & GCH\&SS1 & $0,0,0,0$ \\
General Culture/Humanities \& Social Sciences 2 & GCH\&SS2 & $0,0,0,0$ \\
General Culture/Humanities \& Social Sciences 3 & GCH\&SS3 & $0,0,0,0$ \\
Electric Energy Conversion & ELEC 411 & $4,0,0,0$ \\
Electric Energy Conversion Laboratory (1) & ELEC 481 & $4,0,0,0$ \\
Control Systems & ELEC 431 & $4,0,0,3$ \\
Instrumentation \& Control Laboratory (1) & ELEC 433 & $4,0,0,3$ \\
Data Communications \& Networks & ECOM 432 & $5,0,0,1$ \\
Data Communications \& Networks Laboratory (1) & ECOM 442 & $5,0,0,1$ \\
Computer Architecture \& Organization & ELEC 462 & $2,0,0,0$ \\
Power Systems & ELEC 472 & $4,0,0,3$ \\
Industrial Training (15) & ELEC 495 & $4,1,2,0$ \\
Graduation Project I & ELEC 585 & $5,1,1,0$ \\
Graduation Project II & ELEC 590 & $6,0,0,0$ \\
Digital Signal Processing & ECOM 451 & $5,0,0,0$ \\
Digital Electronics & ELEC 512 & $5,0,0,0$ \\
Advanced Control Systems & ELEC 521 & $5,0,0,0$ \\
Industrial Automation & ELEC 522 & $5,0,0,0$ \\
Special Topics in Power \& Control Engineering & ELEC 530 & $5,0,0,0$ \\
Power System Analysis & ELEC 531 & $5,0,0,0$ \\
Very Large Scale Integration & ELEC 533 & $5,0,0,0$ \\
Power System Distribution & ELEC 534 & $5,0,0,0$ \\
Digital Image Processing & ELEC 551 & $4,0,0,0$ \\
Computer Networks & ELEC 552 & $6,0,0,0$ \\
Java Programming Applications & ELEC 561 & $2,0,0,0$ \\
Embedded Systems Design & ELEC 562 & $2,0,0,0$ \\
Special Topics in Computer Engineering & ELEC 570 & $2,0,0,0$ \\
Special Topics in Electronics Engineering & ELEC 580 & $5,0,0,0$ \\
Analog Integrated Circuit Design & ELEC 582 & $5,0,0,0$ \\
Power Electronics & ELEC 592 & $5,0,0,0$ \\
\hline \hline
\end{tabular}


Study plan for student \# 200935136

There are total 67 courses, and these are:

HSS_105, ISLM_1103, ESPU_107, ESPU_1452, GCH\&SS_1, GCH\&SS_2, GCH\&SS_3, GENG_250, STAT_220, GENG_200, GENG_215, GENG_220, MATH_1110, MATH_1120, MATH_2210, MATH_2220, PHYS_1110, PHYS_1120, CHEM_111, CHEM_175, GENG_315, CHEM_2706, ELEC_305, ELEC_310, ELEC_315, ELEC_320, ELEC_325, ELEC_330, ELEC_335, ELEC_345, ELEC_360, ECOM_360, ELEC_370, ELEC_375, ELEC_411, ELEC_431, ECOM_432, ELEC_433, ECOM_442, ELEC_451, ELEC_461, ELEC_462, ELEC_472, ELEC_481, ELEC_495, ELEC_585, ELEC_590, ECOM_451, ELEC_512, ELEC_521, ELEC_522, ELEC_530, ELEC_531, ELEC_533, ELEC_534, ELEC_551, ELEC_552, ELEC_561, ELEC_562, ELEC_570, ELEC_580, ELEC_582, ELEC_592, PHYS_235, PHYS_330, MATH_245, MATH_470

There are 50 courses offered in Spring 2017, and these are: |

HSS_105, ISLM_1103, ESPU_107, ESPU_1452, GCH\&_SS_1, GCH\&SS_2, GCH\&SS_3, GENG_250, STAT_220, GENG_200, GENG_215, GENG_220, MATH_1110, MATH_1120, MATH_2210, MATH_2220, PHYS_1110, PHYS_1120, CHEM_111, CHEM_175, GENG_315, CHEM_2706, ELEC_305, ELEC_310, ELEC_315, ELEC_320, ELEC_325, ELEC_330, ELEC_335, ELEC_345, ELEC_360, ECOM_360, ELEC_370, ELEC_375, ECOM_432, ECOM_442, ELEC_451, ELEC_461, ELEC_462, ELEC_472, ELEC_495, ELEC_585, ELEC_590, ELEC_552, ELEC_534, ELEC_562, ELEC_580, ELEC_592, PHYS_235, MATH_245

The student has taken 23 courses and these are:

ISLM_1103, ESPU_107, ESPU_1452, GCH\&SS_1, GENG_250, STAT_220, GENG_200, GENG_220, MATH_1110, MATH_1120, MATH_2210, MATH_2220, PHYS_1110, PHYS_1120, MATH_470, CHEM_111, CHEM_175, GENG_315, ELEC_305, ELEC_310, ELEC_330, ELEC_335, ELEC_345

There are 11 possible courses to choose from:

HSS_105, GCH\&SS_2, GCH\&SS_3, GENG_215, CHEM_2706, ELEC_315, ELEC_320, ELEC_325, ELEC_360, ELEC_451, ELEC_461

The possible courses after sorting according to field priority are:

[['ELEC_360', 3, 3, 5, 1], ['ELEC_320', 3, 3, 3, 0], ['ELEC_315', 3, 2, 2, 0], ['ELEC_325', 2, 0, 0, 0], ['ELEC_451', 1, 1, 1, 2], ['ELEC_461', 1, 1, 1, 2], ['CHEM_2706', 1, 0, 0, 0], ['GENG_215', 0, 0, 0, 0], ['HSS_105', 0, 0, 0, 0], ['GCH\&SS_2', 0, 0, 0, 0], ['GCH\&SS_3', 0, 0, 0, 0]]

The final list of sorted possible courses (without their field priority info) is:

['ELEC_360', 'ELEC_320', 'ELEC_315', 'ELEC_325', 'ELEC_451', 'ELEC_461', 'CHEM_2706', 'GENG_215', 'HSS_105', 'GCH\&_SS_2', 'GCH\&SS_3']

The selected ones are: ELEC_360, ELEC_320, ELEC_315, ELEC_325, ELEC_451, ELEC_461

Fig. 2. Course selection process for the first student example.

Table 3. Course Selection for the First Student Example

\begin{tabular}{cccccc}
\hline \hline & Course Code & 1 & 2 & 3 & 4 \\
\hline 1 & ELEC 360 $\checkmark$ & 3 & 3 & 5 & 1 \\
2 & ELEC 320 $\checkmark$ & 3 & 3 & 3 & 0 \\
3 & ELEC 315 $\checkmark$ & 3 & 2 & 2 & 0 \\
4 & ELEC 325 $\checkmark$ & 2 & 0 & 0 & 0 \\
5 & ELEC 451 $\checkmark$ & 1 & 1 & 1 & 2 \\
6 & ELEC 461 $\checkmark$ & 1 & 1 & 1 & 2 \\
7 & CHEM 2706 & 1 & 0 & 0 & 0 \\
8 & GENG 215 & 0 & 0 & 0 & 0 \\
9 & HSS 105 & 0 & 0 & 0 & 0 \\
10 & GCH\&SS_2 & 0 & 0 & 0 & 0 \\
11 & GCH\&SS_3 & 0 & 0 & 0 & 0 \\
\hline \hline
\end{tabular}

In the next stage, the knowledge area associated with each course is tested to find an appropriate list level of the courses based on field priorities. Table III shows a final selection of 11 possible courses sorted first according to the need for industrial training and then to their field priorities.

As the first field that belongs to reverse hierarchy has the highest priority, seven out of 11 courses have a value above ' $O$ ' and therefore fall in this group. Thus, reducing the choice of course selection from 11 to seven. First four courses are initially selected because of priority value of above ' 1 '.

The next field is now tested for the remaining three courses with the same field value of ' 1 ' from the previous level. A ' 1 ' in this field helps select the next and remaining two courses of ELEC 451 \& ELEC 461, respectively. Therefore, six most appropriate courses with 16 credits are selected for this specific student example. The second example student has completed 17 courses as shown in Fig. 3. The system evolves to show 13 possible courses, which the student is eligible to take.

Table IV shows the 13 possible courses with their associated fields sorted according to the field priorities. All 13 courses are required for the industrial training as indicated by Table I. A ' 2 ' in the first field selects five courses as shown. Next course selection is a choice between four courses with a ' 1 ' in the same field. However, the sixth course is selected based on the last field $\left(4^{\text {th }}\right)$ because the first three field values are 
same for all courses. Therefore, six most appropriate courses with 16 credits are selected for this specific student example.

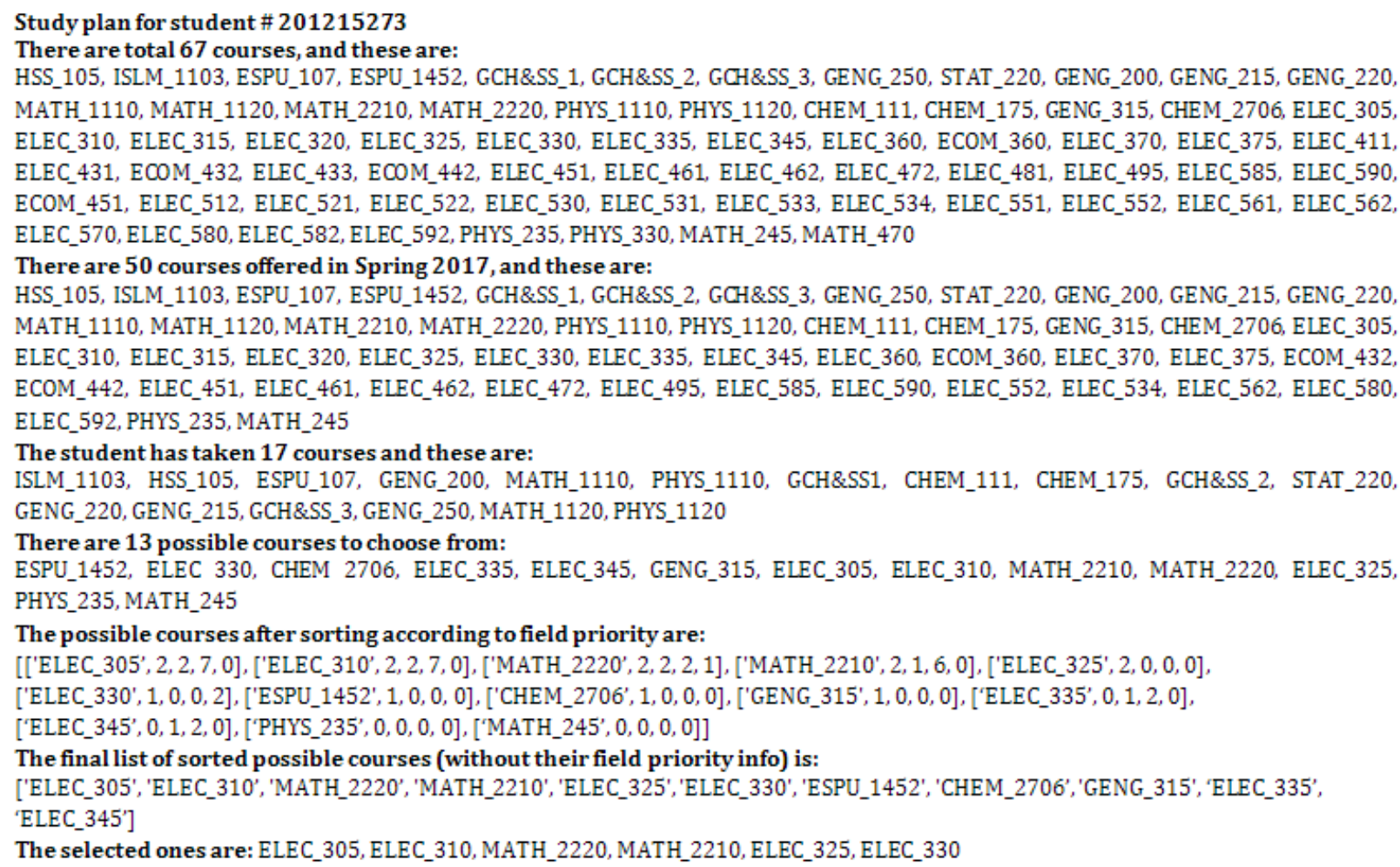

Fig. 3. Course selection process for the second student example.

The third example student has completed 33 out of 51 required courses as shown in Fig. 4. The system evolves to show 12 possible courses, which the student is eligible to take as the prerequisite requirements for these courses have been satisfied.

Table 4. Course Selection for the Second Student Example

\begin{tabular}{cccccc}
\hline \hline & Course Code & 1 & 2 & 3 & 4 \\
\hline 1 & ELEC 305 & 2 & 2 & 7 & 0 \\
2 & ELEC 310 $\checkmark$ & 2 & 2 & 7 & 0 \\
3 & MATH 2220 $\checkmark$ & 2 & 2 & 2 & 1 \\
4 & MATH 2210 $\checkmark$ & 2 & 1 & 6 & 0 \\
5 & ELEC 325 & 2 & 0 & 0 & 0 \\
6 & ELEC 330 $\checkmark$ & 1 & 0 & 0 & 2 \\
7 & ESPU 1452 & 1 & 0 & 0 & 0 \\
8 & CHEM 2706 & 1 & 0 & 0 & 0 \\
9 & GENG 315 & 1 & 0 & 0 & 0 \\
10 & ELEC 335 & 0 & 1 & 2 & 0 \\
11 & ELEC 345 & 0 & 1 & 2 & 0 \\
12 & PHYS 235 & 0 & 0 & 0 & 0 \\
13 & MATH 245 & 0 & 0 & 0 & 0 \\
\hline \hline
\end{tabular}

Table V shows the 12 possible courses with their associated fields sorted according to the industrial training and field priorities. The first five courses are required for industrial training however four courses are selected from this category because only one Basic Mathematics \& Sciences elective is required. Another three courses are selected with a ' 5 ' in the same field. Therefore, a total of seven courses with 17 
credits are selected for this student example.

Study plan for student \# 200937147

There are total 67 courses, and these are:

HSS_105, ISLM_1103, ESPU_107, ESPU_1452, GCH\&SS_1, GCH\&SS_2, GCH\&SS_3, GENG_250, STAT_220, GENG_200, GENG_215, GENG_220, MATH_1110, MATH_1120, MATH_2210, MATH_2220, PHYS_1110, PHYS_1120, CHEM_111, CHEM_175, GENG_315, CHEM_2706, ELEC_305, ELEC_310, ELEC_315, ELEC_320, ELEC_325, ELEC_330, ELEC_335, ELEC_345, ELEC_360, ECOM_360, ELEC_370, ELEC_375, ELEC_411, ELEC_431, ECOM_432, ELEC_433, ECOM_442, ELEC_451, ELEC_461, ELEC_462, ELEC_472, ELEC_481, ELEC_495, ELEC_585, ELEC_590, ECOM_451, ELEC_512, ELEC_521, ELEC_522, ELEC_530, ELEC_531, ELEC_533, ELEC_534, ELEC_551, ELEC_552, ELEC_561, ELEC_562, ELEC_570, ELEC_580, ELEC_582, ELEC_592, PHYS_235, PHYS_330, MATH_245, MATH_470

There are 50 courses offered in Spring 2017, and these are:

HSS_105, ISLM_1103, ESPU_107, ESPU_1452, GCH\&SS_1, GCH\&SS_2, GCH\&SS_3, GENG_250, STAT_220, GENG_200, GENG_215, GENG_220, MATH_1110, MATH_1120, MATH_2210, MATH_2220, PHYS_1110, PHYS_1120, CHEM_111, CHEM_175, GENG_315, CHEM_2706, ELEC_305, ELEC_310, ELEC_315, ELEC_320, ELEC_325, ELEC_330, ELEC_335, ELEC_345, ELEC_360, ECOM_360, ELEC_370, ELEC_375, ECOM_432, ECOM_442, ELEC_451, ELEC_461, ELEC_462, ELEC_472, ELEC_495, ELEC_585, ELEC_590, ELEC_552, ELEC_534, ELEC_562, ELEC_580, ELEC_592, PHYS_235, MATH_245

The student has taken 33 courses and these are:

ISLM_1103, HSS_105, ESPU_107, ESPU_1452, GCH\&SS 1, GENG_250, STAT_220, GENG_200, GENG_215, GENG_220, MATH_1110, MATH_1120, MATH_2210, MATH_2220, PHYS_1110, PHYS_1120, CHEM_111, CHEM_175, CHEM_2706, ELEC_305, ELEC_310, ELEC_330, ELEC_335, ELEC_345, ELEC_360, ELEC_315, ELEC_320, ELEC_431, ECOM_360, ELEC_325, GCH\&SS_2, ELEC_451, ELEC 461

There are 12 possible courses to choose from:

GCH\&SS_3, GENG_315, ELEC_370, ELEC_375, ELEC_462, ELEC_562, ELEC_472, ELEC_552, ELEC_432, ELEC_442, PHYS_235, MATH_245

The possible courses after sorting according to field priority are:

[['ELEC_370', 4, 0, 0, 5], ['ELEC_375', 4, 0, 0, 5], ['GENG_315', 1, 0, 0, 0], ['PHYS_235', 0, 0, 0, 0], ['MATH_245', 0, 0, 0, 0],

['ELEC_432', 5, 0, 0, 1], ['ELEC_442', 5, 0, 0, 1], ['ELEC_552', 6, 0, 0, 0], ['ELEC_472', 4, 0, 0, 3], ['ELEC_462', 2, 0, 0, 0],

['ELEC_562', 2, 0, 0, 0], ['GCH\&:SS3', 0, 0, 0, 0]]

The final list of sorted possible courses (without their field priority info) is:

['ELEC_370', 'ELEC_375', 'GENG_315', 'PHYS_235', 'MATH_245', 'ELEC_432', 'ELEC_442', 'ELEC_552', 'ELEC_472', 'ELEC_462', 'ELEC_562', 'GCH\&SS_3']

The selected ones are: ELEC_370, ELEC_375, GENG_315, PHYS_235, ELEC_432, ELEC_442, ELEC_552

Fig. 4. Course selection process for the third student example.

Fig. 5 shows the test case result of the fourth example student. In this case, the student has completed 22 courses. From the list of 50 courses offered, 14 courses are found eligible to be a part of the selection process. Table VI shows the 14 possible courses with their associated fields sorted according to the field priorities.

Table 5. Course Selection for the Third Student Example

\begin{tabular}{cccccc}
\hline \hline & Course Code & 1 & 2 & 3 & 4 \\
\hline 1 & ELEC 370 $\checkmark$ & 4 & 0 & 0 & 5 \\
2 & ELEC 375 $\checkmark$ & 4 & 0 & 0 & 5 \\
3 & GENG 315 $\checkmark$ & 1 & 0 & 0 & 0 \\
4 & PHYS 235 $\checkmark$ & 0 & 0 & 0 & 0 \\
5 & MATH 245 & 0 & 0 & 0 & 0 \\
6 & ELEC 432 $\checkmark$ & 5 & 0 & 0 & 1 \\
7 & ELEC 442 $\checkmark$ & 5 & 0 & 0 & 1 \\
8 & ELEC 522 $\checkmark$ & 5 & 0 & 0 & 0 \\
9 & ELEC 472 & 4 & 0 & 0 & 3 \\
10 & ELEC 462 & 2 & 0 & 0 & 0 \\
11 & ELEC 562 & 2 & 0 & 0 & 0 \\
12 & GCH\&SS_3 & 0 & 0 & 0 & 0 \\
\hline \hline
\end{tabular}

First course of ELEC 315 is selected because of a '3' in the first field. Another three courses of MATH 2220, MATH 2210, \& ELEC 325 are selected because of a '2' in the same field. Finally, ELEC 330 and GENG 315 are selected because of ' 1 ' in the same first field.

The system is under test in the department and modifications are under way to suit the needs of student and the department. Once the testing phase is complete, EE-CPSS package will be expanded to suit other departments of the college. 


\section{Study plan for student \# 201112134}

There are total 67 courses, and these are:

HSS_105, ISLM_1103, ESPU_107, ESPU_1452, GCH\&SS_1, GCH\&SS_2, GCH\&SS_3, GENG_250, STAT_220, GENG_200, GENG_215, GENG_220, MATH_1110, MATH_1120, MATH_2210, MATH_2220, PHYS_1110, PHYS_1120, CHEM_111, CHEM_175, GENG_315, CHEM_2706, ELEC_305, ELEC_310, ELEC_315, ELEC_320, ELEC_325, ELEC_330, ELEC_335, ELEC_345, ELEC_360, ECOM_360, ELEC_370, ELEC_375, ELEC_411, ELEC_431, ECOM_432, ELEC_433, ECOM_442, ELEC_451, ELEC_461, ELEC_462, ELEC_472, ELEC_481, ELEC_495, ELEC_585, ELEC_590, ECOM_451, ELEC_512, ELEC_521, ELEC_522, ELEC_530, ELEC_531, ELEC_533, ELEC_534, ELEC_551, ELEC_552, ELEC_561, ELEC_562, ELEC_570, ELEC_580, ELEC_582, ELEC_592, PHYS_235, PHYS_330, MATH_245, MATH_470

There are 50 courses offered in Spring 2017, and these are:

HSS_105, ISLM_1103, ESPU_107, ESPU_1452, GCH\&SS_1, GCH\&SS_2, GCH\&SS_3, GENG_250, STAT_220, GENG_200, GENG_215, GENG_220, MATH_1110, MATH_1120, MATH_2210, MATH_2220, PHYS_1110, PHYS_1120, CHEM_111, CHEM_175, GENG_315, CHEM_2706, ELEC_305, ELEC_310, ELEC_315, ELEC_320, ELEC_325, ELEC_330, ELEC_335, ELEC_345, ELEC_360, ECOM_360, ELEC_370, ELEC_375, ECOM_432, ECOM_442, ELEC_451, ELEC_461, ELEC_462, ELEC_472, ELEC_495, ELEC_585, ELEC_590, ELEC_552, ELEC_534, ELEC_562, ELEC_580, ELEC_592, PHYS_235, MATH_245

The student has taken 22 courses and these are:

ESPU_107, MATH_1110, PHYS_1110, ESPU_1452, CHEM_111, CHEM_175, GENG_250, STAT_220, GENG_200, MATH_1120, ELEC_305, ELEC_310, ELEC_335, ELEC_345, GENG_220, CHEM_2706, ELEC_320, ELEC_451, ELEC_461, PHYS_330, PHYS_1120, GCH\&:SS_1

There are 14 possible courses to choose from:

HSS_105, ISLM_1103, GCH\&SS2, GCH\&SS3, GENG_215, MATH_2210, MATH_2220, GENG_315, ELEC_315, ELEC_325, ELEC_330, ELEC_462, ELEC_472, ELEC_562

The possible courses after sorting according to field priority are:

['ELEC_315', 3, 2, 2, 0], ['MATH_2220', 2, 2, 2, 1], ['MATH_2210', 2, 1, 6, 0], ['ELEC_325', 2, 0, 0, 0], ['ELEC_330', 1, 0, 0, 2],

['GENG_315', 1, 0, 0, 0], ['GENG_215', 0, 0, 0, 0], ['ELEC_472', 4, 0, 0, 3], ['ELEC_462', 2, 0, 0, 0], ['ELEC_562', 2, 0, 0, 0],

['HSS_105', 0, 0, 0, 0], ['ISLM_1103', 0, 0, 0, 0], ['GCH\&SS_2', 0, 0, 0, 0], ['GCH\&SS_3', 0, 0, 0, 0]]

The final list of sorted possible courses (without their field priority info) is:

['ELEC_315', 'MATH_2220', 'MATH_2210', 'ELEC_325', 'ELEC_330', 'GENG_315', 'GENG_215', 'ELEC_472', 'ELEC_462', 'ELEC_562', 'HSS_105', 'ISLM_1103', 'GCH\&_SS_2', 'GCH\&SS_3']

The selected ones are: ELEC_315, MATH_2220, MATH_2210, ELEC_325, ELEC_330, GENG_315

Fig. 5. Course selection process for the fourth student example.

Table 6. Course Selection for the Fourth Student Example

\begin{tabular}{cccccc}
\hline \hline & Course Code & 1 & 2 & 3 & 4 \\
\hline 1 & ELEC 315 $\checkmark$ & 3 & 2 & 2 & 0 \\
2 & MATH_2220 $\checkmark$ & 2 & 2 & 2 & 1 \\
3 & MATH_2210 $\checkmark$ & 2 & 1 & 6 & 0 \\
4 & ELEC 325 $\checkmark$ & 2 & 0 & 0 & 0 \\
5 & ELEC 330 $\checkmark$ & 1 & 0 & 0 & 2 \\
6 & GENG 315 $\checkmark$ & 1 & 0 & 0 & 0 \\
7 & GENG 215 & 0 & 0 & 0 & 0 \\
8 & ELEC 472 & 4 & 0 & 0 & 3 \\
9 & ELEC 462 & 2 & 0 & 0 & 0 \\
10 & ELEC 562 & 2 & 0 & 0 & 0 \\
11 & HSS_105 & 0 & 0 & 0 & 0 \\
12 & ISLM_1103 & 0 & 0 & 0 & 0 \\
13 & GCH\&SS_2 & 0 & 0 & 0 & 0 \\
14 & GCH\&SS_3 & 0 & 0 & 0 & 0 \\
\hline \hline
\end{tabular}

\section{Conclusion}

Student course planning is an important process to ensure that students fulfill their graduation requirement without encountering unnecessary delays. A EE Course Planning Software System based on four priority fields built around each course is devised to guide students in selecting from four to seven most appropriate courses suitable for online registration in the next semesters.

\section{References}

[1] Egan, K. D. (2014). Empowerment through advising in individualized major programs. The Mentor: An Academic Advising Journal.

[2] McFarlane, B. L. (2013). Academic advising structures that support first-year student success and 
retention. Dissertations and Theses, Paper 1044.

[3] Daly, M., \& Sidell, N. (2013). Assessing academic advising: A developmental approach. Journal of Baccalaureate Social Work, 18(1), 37-49.

[4] Muola, J. M., Maithya, R., \& Mwinzi, A. M. (2011). The effect of academic advising on academic performance of university students in Kenyan universities. International Multidisciplinary Journal, Ethiopi, 5(5), 332-345.

[5] Werghi, N., \& Kamoun, F. K. (2010). A decision-tree-based system for student academic advising and planning in information systems programmes. International Journal of Business Information Systems, 5(1), 1-18.

[6] Hsu, S., Marques, O., Ilyas, M., \& Ding, X. (2002). Web-based undergraduate academic advising system. Proceedings of International Conference on Engineering Education.

[7] Marques, O., Ding, X., \& Hsu, S. (2001). Design and development of a web-based academic advising system. Proceedings of $31^{\text {st }}$ ASEE/IEEE Frontiers in Education Conference.

[8] Hingorani, K., \& Askari-Danesh, N. (2014). Design and development of an academic advising system for improving retention and graduation. Issues in Information Systems, 15(2), 344-349.

[9] Ishak, I. B. (2012). A conceptual framework of web-based academic advisory information system. Proceedings of 2012 IEEE Symposium on Humanities, Science and Engineering Research, 957-961.

[10] Johnson, S. (1999). Software architecture document for course registration system version 1.0. Technical Report. Wylie College IT.

[11] Feghali, T., Zbib, I., \& Hallal, S. (2011). A web-based decision support tool for academic advising. Educational Technology \& Society Journal, 14(1), 82-94.

[12] Laghari, M. S., Memon, Q. A., \& Habib-ur-Rehman. (2005). Advising for course registration: A UAE university perspective. Proceedings of the International Conference on Engineering Education.

[13] Laghari M. S., \& Khuwaja, G. A. (2012). Course advising and planning for electrical engineering department. WJEIS, 2, 172-181.

[14] Laghari, M. S. (2014). Automated course advising system. IJMLC, 4, 47-51.

[15] Laghari, M. S., Al Habsi, S. A. A., Maaz, N. A., \& Al Naqbi, M. A. A. (2015). A one-semester course planner for EE students. International Research Journal of Electronics \& Computer Engineering, 1(1), 13-18.

[16] Laghari, M. S. (2016). Knowledge based course planning system for EE students at UAE university. JCP, 11(6), 455-463.

[17] Laghari, M. S. (2017). A priority based course planning system for electrical engineering department. IJIET, 7(11), 818-824.

[18] Nambiar, A. N., \& Dutta, A. K. (2010). Expert system for student advising using JESS. Proceedings of the International Conference on Educational and Information Technology.

[19] Marques, O., Ding, X., \& Hsu, S. (2001). Design and development of a Web-Based academic advising system. Proceedings of the $31^{\text {st }}$ ASEE/IEEE Frontiers in Education Conference.

[20] Pumpuang, P., Srivihok, A., Praneetpolgrang, P., \& Numprasertchai, S. (2008). Using Bayesian Network for planning course registration model for undergraduate students. Proceedings of the second IEEE International Conference on Digital Ecosystems and Technologies.

[21] Anantatmula, V. (2010). Project planning techniques for academic advising and learning. MountainRise, the International Journal of the Scholarship of Teaching and Learning, 6(1), 1-18.

[22] Gonzalez, V., \& Esparza, D. (2010). Work in progress - Advising tool to improve the time for graduation and the transfer of students from a community college to engineering school. Proceedings of the $40^{\text {th }}$ ASEE/IEEE Frontiers in Education Conference.

[23] McMahan, B. (2010). An automatic dialog system for student advising. Journal of Undergraduate 
Research at Minnesota State University, Mankato, 10(6).

[24] Albalooshi, F., \& Shatnawi, S. (2010). HE-Advisor: A multidisciplinary web-based higher education advisory system. Global Journal of Computer Science \& Technology, 10(7), 37-49.

[25] Kumar, P., \& Girija, P. N. (2016). A User Interface Design for Semester Course Registration System. International Journal of Innovative Research in Computer and Communication Engineering, 4(7), 14204-14207.

Mohammad S. Laghari was born in Karachi, Pakistan. He received his B.E. degree in electronic engineering from Mehran University of Engineering and Technology, Jamshoro, Sind, Pakistan, M.S. degree in electrical engineering from Drexel University, Philadelphia, Pennsylvania, USA, and Ph.D. in computer engineering from the University of Wales, Swansea, UK in 1980, 1983, and 1993, respectively.

He has taught at the Kuwait University, King Saud University and is currently an associate professor in the Electrical Engineering Department, United Arab Emirates University, U.A.E. His research interests are in applied artificial intelligence, image processing, pattern recognition, and software systems. He has published more than 85 papers in these areas.

Dr. Laghari is a member of the IACSIT (Singapore), PEC (Pakistan), UACEE (USA), and IRED (USA). 